Mul t i pl e i nf I ammat or y cyt oki ne- pr oduct i ve ThyL- 6 cel I I i ne establ i shed from a pat i ent wi th thymic car ci noma

\begin{tabular}{|c|c|}
\hline 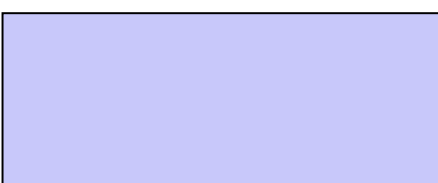 & $\begin{array}{l}\text { I NAl Kuni hi ko, TAKAG Kazut aka, TAKI MOTO } \\
\text { Nobuo, OKADA H r omi, I MAMURA Yoshi aki, UEDA } \\
\text { Takanor i, NAI K H ronobu, NORI K Sakon }\end{array}$ \\
\hline $\begin{array}{l}\text { j our nal or } \\
\text { publ i cat } i \text { on } t i t l e\end{array}$ & Cancer Sci ence \\
\hline vol une & 99 \\
\hline number & 9 \\
\hline page $r$ ange & 17781784 \\
\hline year & $2008-09$ \\
\hline URL & ht t p: //hdl . handl e. net /10098/1826 \\
\hline
\end{tabular}




\title{
Multiple Inflammatory Cytokine-Productive ThyL-6 Cell Line Established from a Patient with Thymic Carcinoma
}

\author{
Kunihiro Inai ${ }^{1}$, Kazutaka Takagi ${ }^{2}$, Nobuo Takimoto ${ }^{1}$, Hiromi Okada ${ }^{1}$, Yoshiaki \\ Imamura $^{3}$, Takanori Ueda ${ }^{2}$, Hironobu Naiki ${ }^{1}$, and Sakon Noriki ${ }^{4}$ \\ ${ }^{1}$ Division of Molecular Pathology, Department of Pathological Sciences, ${ }^{2}$ Division of \\ Hematology and Cardiology, Department of General Medicine, ${ }^{3}$ Division of Surgical \\ Pathology and ${ }^{4}$ Division of Tumor Pathology, Department of Pathological Sciences, \\ Faculty of Medical Sciences, University of Fukui, Fukui 910-1193, Japan
}

Corresponding author:

Kazutaka Takagi, M.D.

23-3 Matsuoka-Shimoaizuki, Eiheiji, Fukui 910-1193, Japan

\author{
Phone: +81-776-61-3111, ext. 2296 \\ Fax: +81-776-61-8109 \\ E-mail: ktakagi@u-fukui.ac.jp
}

Running title: Inflammatory Cytokine Productive ThyL-6 Cell 


\section{Summary}

Thymic epithelial cells can produce many kinds of cytokines, and interleukin (IL)-6-producing thymic carcinoma cases have been reported. However, a cytokine-producing human thymic tumor cell line has not previously been established. In this paper, we report a novel, multiple inflammatory cytokine-productive cell line that was established from a patient with thymic carcinoma. This cell line, designated ThyL-6, positively expressed epithelial membrane antigen, cytokeratins, vimentin intermediate filament, and CD5, although hematological markers were not present in the cells. Cytokine antibody array analysis showed that the cells secreted several cytokines including IL-1 $\alpha$, IL-6, IL-8, RANTES, soluble TNF $\alpha$-receptor 1, VEGF, and CTLA into the culture medium. The addition of ThyL-6-cultured supernatant supported the growth of human myeloma ILKM-3 cells, which require the presence of IL-6 in the culture medium for the maintenance of cell growth, suggesting that the secreted IL-6 from ThyL-6 cells was biologically active. Chromosome analysis demonstrated that ThyL-6 cells w complex karyotype anomalies, including der(16)t(1;16); the latter has been recognized in thymic squamous cell carcinoma and thymic sarcomatoid carcinoma cases, as well as in several other kinds of malignancies. Heterotransplantation of the cells into nude mice showed tumorigenesis with neutrophil infiltration and liquefactive necrosis. These findings suggest that ThyL-6 cells will provide us with a new experimental tool for investigating not only the pathogenesis, biological behavior, chromosomal analysis, and therapeutic reagents of human thymic carcinoma, but also for studying cytokine-chemokine network systems. 
Key words: angiogenesis, autocrine, chemokine, inflammatory cytokine, thymic carcinoma

Abbreviations: cytokeratin: CK, cytotoxic T lymphocyte antigen: CTLA, C-reactive protein: CRP, enzyme immuno assay: EIA, interleukin: IL, leukemia common antigen: LCA, Regulated upon Activation, Normal T-cell Expressed, and Secreted: RANTES, soluble TNF $\alpha$-receptor: sTNFR, vascular endothelial growth factor: VEGF. 


\section{Introduction}

The thymus is known to develop multiple types of neoplasms including thymomas, germ cell tumors, neurogenic tumors, lymphoblastic leukemias/ lymphomas, and other tumors. Thymic epithelial tumors are rare, but are the most common neoplasm of the anterior mediastinum. Thymoma shows an indolent course, thymic carcinoma exhibits a heterogeneous group of aggressive epithelial malignancies, ${ }^{1,2}$ and the epithelial tumors are divided into 11 subtypes in the WHO classification. ${ }^{3}$ Biologically, human thymic epithelial cells have been shown to produce many cytokines, including interleukin (IL) -1 $\alpha$, IL-3, IL-6, IL-7, IL-8, granulocyte macrophage-colony stimulating factor (GM-CSF), G-CSF, M-CSF, leukemia inhibitory factor, and transforming growth factor $\alpha$, that are likely to contribute to thymocyte differentiation. ${ }^{4,5}$ This ability carries with it a risk of developing various cytokine-producing tumors from the thymic epithelial neoplasms. In fact, several case reports have described the existence of IL-6 producing thymic carcinomas. ${ }^{6,7}$ On the other hand, no cytokine-producing human thymic epithelial tumor cell line has yet been reported, only a mouse thymic stromal cell line which produced M-CSF and IL-6. ${ }^{8}$

Recently, we established and characterized a new inflammatory cytokine-producing cell line, ThyL-6, derived from a patient with thymic carcinoma. Because the establishment of cell lines is important for the investigation of the pathophysiological characteristics of diseases, biochemical analysis, and drug discovery, as well as the production of bio sources, the establishment of a ThyL-6 cell line would contribute to the investigation of the pathogenesis and biological behavior of thymic carcinoma, therapeutic reagents against it, and the study of cytokine-chemokine network systems. To our knowledge, ThyL-6 is the first cytokine productive human thymic 
carcinoma cell line.

\section{Materials and Methods}

Patient.

A 57-year-old male without a history of smoking was admitted to The University of Fukui Hospital because of a mediastinal tumor and leukocytosis. Histological inspection was performed by his primary doctor, and he was pathologically diagnosed as having undifferentiated thymic carcinoma. His complete blood cell counts showed leukocytosis with a 27,200 / $\mu$ l white blood cell (WBC) count with $90 \%$ mature neutrophils, normocytic anemia with a $2.35 \times 10^{6} / \mu \mathrm{l}$ red blood cell count, and thrombocytosis with $63.2 \times 10^{4} / \mu$ of platelets, respectively. Body temperature was elevated above $38^{\circ} \mathrm{C}$ and serum C-reactive protein (CRP) was increased to $32.6 \mathrm{mg} / \mathrm{dl}$. Serum uric acid level was low, in the range between 1.7 and $2.3 \mathrm{mg} / \mathrm{dl}$, whereas the serum creatinine level was within the normal range. A uric acid clearance test ${ }^{9}$ showed an excess of uric acid excretion, with a urate clearance (Cua) of $18.2 \mathrm{ml} / \mathrm{min}$, an excretion of uric acid (Eua) of $0.438 \mathrm{mg} / \mathrm{kg} / \mathrm{h}$, and a creatinine clearance (Ccr) of 122 ml/min. Serum interleukin-6 levels measured by Enzyme Immuno Assay (EIA) were increased to $298 \mathrm{pg} / \mathrm{ml}$. The serum levels were dependent on the tumor size because the value was reduced after chemotherapy. Despite several courses of antineoplastic chemotherapies, the tumor progressed and the patient died of pleuritis carcinomatosa. Informed consent was obtained from the patient a family member for this research work, and this research was approved by the ethics/institutional review board of The University of Fukui Hospital and conforms to the provisions of the declaration of Helsinki in 1995. 
Reagents.

RPMI 1640 medium, fetal bovine serum (FBS), 10\% trypsin-EDTA, and an MTT assay kit were purchased from Sigma (St. Louis, MO, USA). A TranSignal Human Cytokine Antibody Array 3.0 kit was purchased from Panomics (Redwood City, CA, USA). Recombinant human IL-6, IL-8, and Regulated upon Activation, Normal T-cell Expressed, and Secreted (RANTES) were purchased from PeproTech EC (London, UK). An anti-human rabbit polyclonal IL-6 antibody, a monoclonal mouse IL-8 antibody (6217.11), and a goat polyclonal RANTES antibody were obtained from Sigma. Anti-human monoclonal CEA (Clone; II-7), EMA (E29), pan-cytokeratin (Pan CK) (AE1/AE3), CK 5/6 (D5/16 B4), CK 7 (OV-TL 12/13), CK 8 (35ßH11), CK 10 (DE-K10), CK 18 (DC 10), CK 19 (BA17), CK 20 (Ks20.8), melanosome (HMB-45), placental alkaline phosphatase (PLAP) (8A9), vimentin (V9), CD5 (CD5/54/F6), CD20cy (L26), CD30 (Ber-H2), CD45 (leukemia common antigen, LCA) (2B11+PO7/26), CD45R0 (UCHL-1), polyclonal CD117, and S100 antibodies were acquired from DAKO (Kyoto, Japan). Secondary HRP conjugated against mouse, goat, and rabbit IgG were obtained from Santa Cruz (Santa Cruz, CA, USA) and a BM Chemiluminescence Western Blotting Kit was purchased from Roche (Indianapolis, IN, USA). For immunohistochemical staining, a HISTOFINE SAB-PO kit (Nichirei, Tokyo, Japan) was used for the secondary reaction. Other general reagents were of the highest purity commercially available.

Animal.

6-week-old male nude mice (BALB/c nu/nu, Sankyo Labo, Tokyo) were 
subcutaneously inoculated in the back with 1 x $10^{6}$ ThyL-6 cells. Two weeks later, the mice were sacrificed and pathological sections were prepared as described previously ${ }^{10}$. The slide sections were stained by hematoxylin and eosin dye, ${ }^{11}$ and the histological findings were evaluated by two different pathologists. Immunohistochemical staining of paraffin-embedded sections was performed as described previously ${ }^{12}$.

Cell culture.

Tumor cells were harvested from the pleural effusion and were cultured in RPMI 1640 medium supplemented with 10\% FBS, penicillin, and streptomycin in a 5\% $\mathrm{CO}_{2}$ atmosphere at $37^{\circ} \mathrm{C}$. The established cell line was designated as ThyL-6. Cell growth was evaluated by trypan-blue dye exclusion assay or MTT assay according to manufacturer's protocol. The exponentially growing cells were used for several experiments. To determine cytokine secretion into the culture medium from the cells, the supernatants were collected at the confluent growth phase and stored at $-80{ }^{\circ} \mathrm{C}$ until analysis. A human multiple myeloma ILKM-3 cell line (kindly provided by Dr. S. Shimizu, Shimane Prefectural Central Hospital), ${ }^{13}$ which requires IL-6 for cell growth, was used for the biological assay.

\section{Immunohistochemical staining.}

To explore the characteristics of the ThyL-6 cells, cells attached to an 8-chamber slide (Nalge Nunc International, Tokyo, Japan) were fixed using 10\% formaldehyde for $8 \mathrm{~min}$. The fixed cells were incubated for 30 min with TBS (pH 7.6) in the presence of $10 \% \mathrm{FBS}$ and 5\% BSA to protect them from the non-specific binding of antibodies. The cells were incubated with anti-human primary antibodies and 
visualized using a HISTOFINE SAB-PO kit according to the manufacturer's instructions.

Chromosome analysis.

For identification of the chromosomes in the ThyL-6 cells, the exponentially growing cells were harvested and their karyotypes were analyzed according to the standard protocol of the Giemsa-banding technique.

Human cytokine antibody array.

A TranSignal Human Cytokine Antibody Array 3.0 kit was used to investigate the secreted cytokine profiles of the ThyL-6 cells. The array membrane was incubated for $2 \mathrm{~h}$ at room temperature in the presence of $2 \mathrm{ml}$ of the supernatant in which the ThyL-6 cells had been cultured for 4 days. The membrane was reacted with biotin-conjugated anti-human cytokine antibodies and then incubated with streptavidine-conjugated HRP. Secreted cytokines were visualized by a Chemiluminescence Image Analyzer (Alpha Innotech, San Leandro, CA, USA) and a BM Chemiluminescence Western Blotting Kit. Quantitative determination of cytokines in the culture medium was performed by EIA using the standard protocol.

Western blotting.

For Western blotting analysis, the supernatant was directly loaded onto a $10 \%$ or $15 \%$ of SDS-PAGE gel with 2 x SDS-PAGE sample buffer (100mM Tris-HCl pH 6.8, 4\% SDS, 20\% Glycerol, 20\% $\beta$-mercaptoethanol, and 0.02\% Bromophenol blue). In some experiments, the supernatant was concentrated by an Ultrafree-MC 10000 NMWL 
Filter Unit (Millipore, Bedford, MA, USA) before sample loading. Separated proteins were transferred onto Immobilon-P $0.45 \mu \mathrm{m}$ PVDF membrane (Millipore) and probed with specific antibodies in TBS-T (25 mM Tris, pH 8.4 supplemented with $130 \mathrm{mM}$ $\mathrm{NaCl}, 5 \mathrm{mM}$ potassium phosphate, $5 \%$ non-fat dry milk, and $0.1 \%$ Tween 20 ) as described previously. ${ }^{14,15}$ Secondary antibodies conjugated to HRP, and a BM Chemiluminescence Western Blotting Kit were used to develop images in a Chemiluminescence Image Analyzer.

\section{Results}

ThyL-6 cell line shows epithelial cell differentiation.

Thymic neoplasms include thymomas, germ cell tumors, carcinoid tumors, lymphoblastic leukemias/lymphomas, neuronal tumors and other tumors. To clarify the origin of the cell line, an immunohistochemical stain was performed. As shown in Figure 1, the cells expressed the epithelial cell markers EMA, Pan CK, CK5/6, CK 7, CK19, CK20, mesenchymal filament vimentin, and CD5, whereas hematological antigens including CD20cy, CD30, CD45, and CD45R0, as well as CEA, melanosome, and PLAP antigens were not detected in the cells. Immunostaining data from the ThyL-6 cells with additional antibodies is summarized in Table 1.

ThyL-6 produces multiple inflammatory cytokines and chemokines.

Interleukin 6 is associated with many reactions including the induction of inflammation, fever generation, thrombocytosis, increase of CRP, and promotion of uric acid excretion. ${ }^{16-19}$ The patient had the following clinical symptoms: high body temperature, thrombocytosis, high CRP value, hypouricemia, and high serum IL-6 level, 
suggesting that the established thymic carcinoma cells were also producing inflammatory cytokines, especially IL-6. Therefore, we investigated the profile of cytokine production using a cytokine antibody array. After incubating the cells in culture medium for 96 hours, the resulting supernatant was found to contain IL-6, IL-8, RANTES, IL-1 $\alpha$, vascular endothelial growth factor (VEGF), soluble TNF $\alpha$-receptor I (sTNFR I), and small amounts of eotoxin and cytotoxic T lymphocyte antigen (CTLA) (Figure 2). We then measured the cytokine concentrations of IL-6, IL-8, RANTES, IL-1 $\alpha$, VEGF, sTNFR I and eotoxin by EIA. The concentrations of IL-6, IL-8, RANTES, IL-1 $\alpha$, VEGF, and sTNFR I were 88,800 \pm 3,111 pg/ml (normal serum level (nsl): $\leq 2.41 \mathrm{pg} / \mathrm{ml}), 88,350 \pm 15,203 \mathrm{pg} / \mathrm{ml}(\mathrm{nsl}:<8.0 \mathrm{pg} / \mathrm{ml}), 526 \pm 237 \mathrm{pg} / \mathrm{ml}$ (nsl: not determined), $502 \pm 132 \mathrm{pg} / \mathrm{ml}$ (nsl: $<7.8 \mathrm{pg} / \mathrm{ml}), 9,625 \pm 1,803 \mathrm{pg} / \mathrm{ml}(\mathrm{nsl}: \leq 38.3$ pg/ml), $542 \pm 57$ pg/ml (nsl: 434 - 930 pg/ml), respectively, whereas eotoxin was not detected by EIA (Table 2). In addition to EIA, we stained IL-6, IL-8, and RANTES using immunohistochemical techniques and found that these cytokines were localized in the cytoplasm (Figure 3). Although Apo1/Fas, Eotoxin, IP-10, Leptin, MMP3, ICAMP-1, IL-4, IL-7, and IL-12 were faintly detected by the cytokine antibody array, we considered them as being background levels already present in either the culture medium or FBS. GM-CSF, EGF, MIP1 $\alpha$, MIP $1 \beta$, MIP-4, MIP-5, TGF $\beta$, IFN $\gamma$, TNFR II, VCAMP-1, IL-1 $\beta$, IL-1R $\alpha$, IL-2, IL-3, IL-5, IL-6R, IL-10, IL-15, and IL-17 could not be detected by the cytokine antibody array (Figure 2).

Chromosomal analysis of ThyL-6 cells.

In the cytogenetic analysis of ThyL-6 cells, twenty metaphases were investigated using the G-band technique. This cell line had two modes of chromosomes, 
with the number of chromosomes being 51 . The consistent karyotype aberrations were 51, XY, +3, i(3) (q10), +7, add(7)(q11), dic(7)t(7;17)(p11;p11), +8, add(8)(p11), i(8)(q10), -9, -13, +15, i(15)(q10), der(16)t(1;16)(q11;q24), der(16)t(9;16)(q11;q24), add(21)(p11), der(?)t(?;q11), +2mar [18] / 51, idem, -der(?)t(?;q11), +mar [2] (Figure 4).

Cell growth of ThyL-6 is associated with the autocrine mechanism of IL-6.

The growth rate of the ThyL-6 cells was evaluated by the trypan-blue dye exclusion method, and the doubling time was calculated at $26.3 \mathrm{~h}$ (Figure 5A). Several cytokines including IL-6, G-CSF, and GM-CSF can stimulate cell proliferation of normal marrow cells as well as several cancer cell lines by autocrine or paracrine mechanisms. To investigate the relevance of autocrine growth, ThyL-6 cells were cultured in the presence of neutralizing anti-human IL-6 or IL-8 antibody, and the growth inhibition was evaluated using an MTT assay. As shown in Figure 5B, the growth of ThyL-6 cells was dose-dependently inhibited in the presence of the anti-IL-6 or IL-8 antibody, and the final volume increase of $10 \%$ when the IL-6 antibody was added to the medium exhibited a significant growth inhibition (35.7 $\pm 5.2 \%$ inhibition of untreated control, $\mathrm{p}<0.05)$, indicating that cell proliferation was partially dependent on the autocrine stimulation of IL-6.

The produced IL-6 was biologically active.

Because the produced IL-6 was likely to be biologically active, we first compared the molecular weight of the produced IL-6 with that of recombinant human IL-6 using Western blotting. As shown in figure 6A, the molecular weight of the 
produced IL-6 was slightly higher than the recombinant protein. When the expressions of IL-8 and RANTES were also compared, the molecular weights of these chemokines were almost the same as those of the recombinant proteins (data not shown). Next, we analyzed the growth of a human multiple myeloma cell line, ILKM-3, because the proliferation of the cells depends on the existence of IL-6 in the culture medium. When the supernatant of the cultured ThyL-6 cells was added to RPMI 1640 medium, the level of growth of the ILKM-3 cells was found to depend on the dose of the culture medium added (Figure 6B).

Histological findings of ThyL-6 cells in nude mice.

To evaluate the tumorigenesis in vivo, 1 x $10^{6}$ of ThyL-6 cells were inoculated subcutaneously into 11 nude mice. Two weeks later, tumors developed in all of them (Figure 7A, 7B). The mice were sacrificed and both paraffin-embedded sections and frozen sections were prepared. As shown in Figures 7C and 7D, the polymorphic cells had round or oval nuclei with a large round nucleolus and these cells invasively proliferated into the backs of the mice with small amounts of interstitial fibrous connective tissue and scattered liquefactive necrosis present. In addition, neutrophils also infiltrated into the tumor nests independent of necrotic tissue. Similar histological findings containing mature granulocytes had been found in the original biopsy sections of the patient (data not shown), suggesting that the ThyL-6 is characterized by the induction of neutrophils-infiltration into the tumor nest.

\section{Discussion}

In the present study, we established and characterized a new cancer cell line 
derived from a patient with undifferentiated thymic carcinoma who had markedly high levels of leukocytosis and thrombocytosis, a high CRP level, a low serum uric acid value, and a high serum IL-6 level. The epithelial nature of ThyL-6 cells was supported by the presence of cellular cytokeratins and EMA, which are known to be specifically expressed in epithelial cells. ${ }^{40} 20$ Several multiple cytokine-producing cell lines have been previously reported involving G-SCF, GM-SCF, IL-6, IL-8, and other cytokines. ${ }^{21-25}$ Regarding inflammatory cytokines, several cell lines secrete both IL-6 and IL-8, ${ }^{26,27}$ and human cervical epithelial cell lines immortalized in retroviral constructs are known to produce IL-6, IL-8, and RANTES. ${ }^{28}$ Similarly, we found that ThyL-6 cells expressed cytoplasmic IL-6, IL-8, and RANTES. In addition, this cell line also secreted IL-1 $\alpha$, sTNFR I, VEGF, and CTLA into the culture medium. Importantly, human thymic epithelial cells have been shown to produce many cytokines, including IL-1 $\alpha$, IL-3, IL-6, IL-7, IL-8, G-CSF, GM-CSF, M-CSF, leukemia inhibitory factor, and transforming growth factor $\alpha$, that are likely to contribute to thymocyte differentiation. ${ }^{4,}$ ${ }^{5}$ Several reports mention that c-Kit (CD117) is a promising diagnostic marker with $80 \%$ of thymic carcinomas positive for it. ${ }^{29,} 30$ In contrast, ThyL-6 cells do not express the marker. However, the histology of the tumor in nude mice corresponded well to that of the Ty-82 thymic carcinoma cells and was compatible with the morphological diagnostic criteria of thymic carcinoma, i.e., with large cell size, prominent nucleoli, high nuclear/cytoplasmic ratio, abundant mitosis, and multifocal confluent necrosis. ${ }^{10}$ In addition, the patient had never smoked. These data suggest that ThyL-6 is a multiple inflammatory cytokine-producing thymic carcinoma derived cell line.

Overproduction or injection of IL-6 leads to acute inflammatory reactions, including fever and a high CRP level. Our patient suffered from a hyper CRP value of 
more than $30 \mathrm{mg} / \mathrm{dl}$, documented fever, hyperleukocytosis, and thrombocytosis, which allowed us to surmise that the patient had an increased serum IL-6 level. In fact, serum IL-6 level was significantly increased in this patient. Using EIA, immunohistochemical staining, and Western blotting, the established ThyL-6 cells were also verified as being able to produce IL-6. Moreover, the secreted IL-6 was shown to be biologically active because the growth of IL-6-dependent ILKM-3 cells was supported in the presence of the supernatant in which the ThyL-6 cells were cultured, suggesting that ThyL-6 can produce a bioavailable grade of human IL-6.

Cytogenetic studies on thymic epithelial tumors are few, and the significance of chromosomal abnormalities is unknown, except for $\mathrm{t}(15 ; 19)(\mathrm{q} 15$;p13), which is possibly related to thymic carcinoma in children and young adults. ${ }^{31}$ A thymic cancer cell line with $\mathrm{t}(15 ; 19)(\mathrm{q} 15 ; \mathrm{p} 13)$, Ty-82, has been established from a patient with undifferentiated thymic carcinoma ${ }^{10}$, and the cell line exhibits EMA without showing any epithelial markers including cytokeratins. Whereas, ThyL-6 cells showed several epithelial markers including EMA, Pan CK, CK 5/6, 7, 8, 18, 19, and 20. In the CKs, CK 5/6 is preferentially expressed in epithelial cells differentiating toward squamous cells. ${ }^{32,33}$ In addition, ThyL-6 cells represented CD5, which is expressed in thymic carcinoma, including thymic squamous cell carcinomas and rare cases of thymoma. Recently, several reports mention that some pulmonary squamous cell carcinoma cases also express CD5. ${ }^{29,} 30$ Taken together with the results, the expression of this molecule in ThyL-6 cells suggests that this cell line may have squamous cell potency.

Genetic analysis, based on comparative genomic hybridization of a relatively large number of thymoma and thymic carcinomas, has demonstrated that aggressive type B3 thymoma and thymic squamous cell carcinoma preferentially show aberrance 
karyotypes with a gain of chromosome 1q. ${ }^{34}$ In the present case, ThyL-6 cells had complex chromosome abnormalities, and showed a 1q gain with the $\operatorname{der}(16) \mathrm{t}(1 ; 16)(\mathrm{q} 11 ; \mathrm{q} 24)$ chromosome in them. Abnormalities of 1q, including trisomy or partial gain of the arm, have been demonstrated to be the most frequent genetic changes in malignant cells, ${ }^{35,36}$ and potentially important growth promoting genes have been demonstrated to map to $1 \mathrm{q} .{ }^{35}$ Chromosome 16 is involved in unbalanced whole arm translocations as a counterpart of chromosome $1,{ }^{36}$ and often constitutes a derivative chromosome, der(16)t(1;16). Der(16)t(1;16) abnormality has been recognized in several tumors including a multiple myeloma, ${ }^{37}$ myelodysplastic syndrome, ${ }^{38}$ Wilms' tumor, ${ }^{39}$ myxoid/round cell liposarcoma, ${ }^{40}$ breast carcinoma, ${ }^{41}$ Ewing's sarcoma, ${ }^{42}$ alveolar rhabdomyosarcoma, ${ }^{36}$ and malignant peripheral nerve sheath tumor with rhabdomyoblastic differentiation. ${ }^{43}$ Regarding thymocytic tumors, this aberrant derivative chromosome formation has been reported in thymic squamous cell carcinoma and thymic sarcomatoid carcinoma cases. ${ }^{44,45}$ Thus, these results suggest that $\operatorname{der}(16) \mathrm{t}(1 ; 16)$ may also play a significant role in the pathophysiology of thymic carcinoma as well as many kinds of malignancies. In addition, cell growth of ThyL-6 cells showed a dose-dependent inhibition after the addition of neutralizing IL-6 antibody. The ThyL-6 cells had another chromosomal translocation on chromosome 17p11, which involves a pseudogene of human gp130 transducer chain gene of IL-6. ${ }^{46}$ Therefore, this cell line may also be useful for studying the autocrine growth mechanisms of IL-6, the IL-6 receptor, or reactivation of the pseudogene.

In conclusion, we established a new multiple inflammatory cytokine-producing cell line. To our knowledge, this is the first such human thymic carcinoma cell line that produces inflammatory cytokines. Although further study is needed, this cell line could 
provide us with a new experimental tool for investigating not only the pathogenesis, biological behavior, chromosomal analysis and therapeutic reagents of thymic carcinoma, but also for studying cytokine-chemokine network systems. 


\section{References}

1 Detterbeck FC, Egan TM. Thoracoscopy using a substernal handport for palpation. Ann Thorac Surg. 2004; 78: 1031-6.

2 Duwe BV, Sterman DH, Musani AI. Tumors of the mediastinum. Chest. 2005; 128: 2893-909.

3 Travis W, Brambilla E, Muller-Hermelink H, Harris C. Pathology and Genetics of Tumours of the Lung, Thymus And Heart Lyon: IARC Press, 2005.

4 Fernandez E, Vicente A, Zapata A, Brera B, Lozano JJ, Martinez C, et al.

Establishment and characterization of cloned human thymic epithelial cell lines. Analysis of adhesion molecule expression and cytokine production. Blood. 1994; 83: 3245-54.

$5 \quad$ Haynes BF, Denning SM, Le PT, Singer KH. Human intrathymic T cell differentiation. Semin Immunol. 1990; 2: 67-77.

$6 \quad$ Ikeda T, Kawakami K, Fujita J, Bandoh S, Yamadori I, Takahara J. Thymic carcinoma associated with a high serum level of interleukin 6 diagnosed through the evaluation for asymptomatic elevation of acute-phase reactants. Intern Med. 1998; 37: 414-6.

7 Matsumura N, Shiiki H, Saito N, Uramoto H, Hanatani M, Nonaka H, et al. Interleukin-6-producing thymic squamous cell carcinoma associated with Castleman's disease and nephrotic syndrome. Intern Med. 2002; 41: 871-4.

8 Lee CK, Kim JK, Kim K, Han SS. A mouse thymic stromal cell line producing macrophage-colony stimulating factor and interleukin-6. Arch Pharm Res. 2000; 23: 252-6. 9 Ichida K, Hosoyamada M, Hisatome I, Enomoto A, Hikita M, Endou H, et al. Clinical and molecular analysis of patients with renal hypouricemia in Japan-influence of URAT1 gene on urinary urate excretion. J Am Soc Nephrol. 2004; 15: 164-73.

10 Kuzume T, Kubonishi I, Takeuchi S, Takeuchi T, Iwata J, Sonobe H, et al. Establishment and characterization of a thymic carcinoma cell line (Ty-82) carrying t(15;19)(q15;p13) chromosome abnormality. Int J Cancer. 1992; 50: 259-64.

11 Inai K, Iwasaki H, Noriki S, Ikegaya S, Yamashita M, Imamura Y, et al. Frequent detection of multidrug-resistant pneumonia-causing bacteria in the pneumonia lung tissues of patients with hematological malignancies. Int J Hematol. 2007; 86: 225-32.

12 Jin Y, Sun A, Noriki S, Imamura Y, Fukuda M. Detection of cancer clones in human colorectal adenoma as revealed by increased DNA instability and other bio-markers. Eur $\mathrm{J}$ Histochem. 2007; 51: 1-10.

13 Shimizu S, Yoshioka R, Hirose Y, Sugai S, Tachibana J, Konda S. Establishment of 
two interleukin 6 (B cell stimulatory factor 2/interferon beta 2)-dependent human bone marrow-derived myeloma cell lines. J Exp Med. 1989; 169: 339-44.

14 Ostapkowicz A, Inai K, Smith L, Kreda S, Spychala J. Lipid rafts remodeling in estrogen receptor-negative breast cancer is reversed by histone deacetylase inhibitor. Mol Cancer Ther. 2006; 5: 238-45.

15 Inai K, Tsutani H, Yamauchi T, Huberman E, Nakamura T, Ueda T. Differentiation induction in non-lymphocytic leukemia cells upon treatment with mizoribine. Int J Hematol. 1997; 66: 335-44.

16 Akira S, Kishimoto T. IL-6 and NF-IL6 in acute-phase response and viral infection. Immunol Rev. 1992; 127: 25-50.

17 Yoshimura A. Signal transduction of inflammatory cytokines and tumor development. Cancer Sci. 2006; 97: 439-47.

18 Tsutani H, Yoshio N, Ueda T. Interleukin 6 reduces serum urate concentrations. J Rheumatol. 2000; 27: 554.

19 Urano W, Yamanaka H, Tsutani H, Nakajima H, Matsuda Y, Taniguchi A, et al. The inflammatory process in the mechanism of decreased serum uric acid concentrations during acute gouty arthritis. J Rheumatol. 2002; 29: 1950-3.

20 Sun TT, Bonitz P, Burns WH. Cell culture of mammalian thymic epithelial cells: growth, structural, and antigenic properties. Cell Immunol. 1984; 83: 1-13.

21 Baba M, Hasegawa H, Nakayabu M, Shimizu N, Suzuki S, Kamada N, et al. Establishment and characteristics of a gastric cancer cell line (HuGC-OOHIRA) producing high levels of G-CSF, GM-CSF, and IL-6: the presence of autocrine growth control by G-CSF. Am J Hematol. 1995; 49: 207-15.

22 Asahi Y, Kubonishi I, Imamura J, Kamioka M, Matsushita H, Furihata M, et al. Establishment of a clonal cell line producing granulocyte colony-stimulating factor and parathyroid hormone-related protein from a lung cancer patient with leukocytosis and hypercalcemia. Jpn J Cancer Res. 1996; 87: 451-8.

23 Kondo K, Okada T, Matsui T, Kato S, Date K, Yoshihara M, et al. Establishment and characterization of a human $\mathrm{B}$ cell line from the lung tissue of a patient with scleroderma; extraordinary high level of IL-6 secretion by stimulated fibroblasts. Cytokine. 2001; 13: 220-6.

24 Li A, Varney ML, Valasek J, Godfrey M, Dave BJ, Singh RK. Autocrine role of interleukin-8 in induction of endothelial cell proliferation, survival, migration and MMP-2 production and angiogenesis. Angiogenesis. 2005; 8: 63-71.

25 Inoue Y, Tsushima H, Ando K, Sawayama Y, Sakai M, Yamasaki R, et al. Chemokine expression in human erythroid leukemia cell line AS-E2: macrophage 
inflammatory protein-3alpha/CCL20 is induced by inflammatory cytokines. Exp Hematol. 2006; 34: 19-26.

26 Sekido Y, Sato M, Usami N, Shigemitsu K, Mori S, Maeda O, et al. Establishment of a large cell lung cancer cell line (Y-ML-1B) producing granulocyte colony-stimulating factor. Cancer Genet Cytogenet. 2002; 137: 33-42.

27 Tachibana M, Miyakawa A, Nakashima J, Murai M, Nakamura K, Kubo A, et al. Autocrine growth promotion by multiple hematopoietic growth factors in the established renal cell carcinoma line KU-19-20. Cell Tissue Res. 2000; 301: 353-67.

28 Fichorova RN, Anderson DJ. Differential expression of immunobiological

mediators by immortalized human cervical and vaginal epithelial cells. Biol Reprod. 1999; 60: 508-14.

29 Hishima T, Fukayama M, Fujisawa M, Hayashi Y, Arai K, Funata N, et al. CD5 expression in thymic carcinoma. Am J Pathol. 1994; 145: 268-75.

30 Nakagawa K, Matsuno Y, Kunitoh H, Maeshima A, Asamura H, Tsuchiya R. Immunohistochemical KIT (CD117) expression in thymic epithelial tumors. Chest. 2005; 128: $140-4$.

31 Sait SN, Brooks JJ, Ashraf M, Zhang PJ. A novel t(1;8)(p13;p11) in a thymic carcinoma with unusual giant cell features and renal metastasis. Cancer Genet Cytogenet. 2001; 124: 140-3.

32 Chu PG, Weiss LM. Expression of cytokeratin 5/6 in epithelial neoplasms: an immunohistochemical study of 509 cases. Mod Pathol. 2002; 15: 6-10.

33 Kaufmann O, Fietze E, Mengs J, Dietel M. Value of p63 and cytokeratin 5/6 as immunohistochemical markers for the differential diagnosis of poorly differentiated and undifferentiated carcinomas. Am J Clin Pathol. 2001; 116: 823-30.

34 Zettl A, Strobel P, Wagner K, Katzenberger T, Ott G, Rosenwald A, et al. Recurrent genetic aberrations in thymoma and thymic carcinoma. Am J Pathol. 2000; 157: 257-66.

35 Knuutila S, Bjorkqvist AM, Autio K, Tarkkanen M, Wolf M, Monni O, et al. DNA copy number amplifications in human neoplasms: review of comparative genomic hybridization studies. Am J Pathol. 1998; 152: 1107-23.

36 McManus AP, Min T, Swansbury GJ, Gusterson BA, Pinkerton CR, Shipley JM. $\operatorname{der}(16) \mathrm{t}(1 ; 16)(\mathrm{q} 21 ; \mathrm{q} 13)$ as a secondary change in alveolar rhabdomyosarcoma. A case report and review of the literature. Cancer Genet Cytogenet. 1996; 87: 179-81.

37 Mugneret F, Sidaner I, Favre B, Manone L, Maynadie M, Caillot D, et al. $\operatorname{Der}(16) \mathrm{t}(1 ; 16)(\mathrm{q} 10 ; \mathrm{p} 10)$ in multiple myeloma: a new non-random abnormality that is frequently associated with Burkitt's-type translocations. Leukemia. 1995; 9: 277-81. 38 Mugneret F, Dastugue N, Favre B, Sidaner I, Salles B, Huguet-Rigal F, et al. 
$\operatorname{Der}(16) t(1 ; 16)(q 11 ; q 11)$ in myelodysplastic syndromes: a new non-random abnormality characterized by cytogenic and fluorescence in situ hybridization studies. Br J Haematol. 1995; 90: 119-24.

39 Sheng WW, Soukup S, Bove K, Gotwals B, Lampkin B. Chromosome analysis of 31 Wilms' tumors. Cancer Res. 1990; 50: 2786-93.

40 Birch NC, Antonescu CR, Nelson M, Sarran L, Neff JR, Seemayer T, et al. Inconspicuous insertion 22;12 in myxoid/round cell liposarcoma accompanied by the secondary structural abnormality der(16)t(1;16). J Mol Diagn. 2003; 5: 191-4.

41 Tsuda H, Takarabe T, Fukutomi T, Hirohashi S. Preferential occurrence of breast carcinomas with loss of chromosome $16 q$ and der $(16)$ t $(1 ; 16)$ / der $(1 ; 16)$ in middle-aged patients with hyperplasia of mammary glands. Jpn J Cancer Res. 2000; 91: 692-9.

42 Mugneret F, Lizard S, Aurias A, Turc-Carel C. Chromosomes in Ewing's sarcoma. II. Nonrandom additional changes, trisomy 8 and der(16)t(1;16). Cancer Genet Cytogenet. 1988; 32: 239-45.

43 Velagaleti GV, Miettinen M, Gatalica Z. Malignant peripheral nerve sheath tumor with rhabdomyoblastic differentiation (malignant triton tumor) with balanced t(7;9)(q11.2;p24) and unbalanced translocation der(16)t(1;16)(q23;q13). Cancer Genet Cytogenet. 2004; 149: 23-7.

44 Sonobe H, Ohtsuki Y, Nakayama H, Asaba K, Nishiya K, Shimizu K. A thymic squamous cell carcinoma with complex chromosome abnormalities. Cancer Genet Cytogenet. 1998; 103: 83-5.

45 Eimoto T, Kitaoka M, Ogawa H, Niwa H, Murase T, Tateyama H, et al. Thymic sarcomatoid carcinoma with skeletal muscle differentiation: report of two cases, one with cytogenetic analysis. Histopathology. 2002; 40: 46-57.

46 Rodriguez C, Grosgeorge J, Nguyen VC, Gaudray P, Theillet C. Human gp130 transducer chain gene (IL6ST) is localized to chromosome band 5q11 and possesses a pseudogene on chromosome band 17p11. Cytogenet Cell Genet. 1995; 70: 64-7. 
Table 1. Immunohistochemical Staining of ThyL-6 Cells

\begin{tabular}{|c|c|c|c|}
\hline Antigen & Clone & Specificity & Thyl-6 \\
\hline Pan-Cytokeratin & AE1 /AE3 & Epithelial cells & ++ \\
\hline Cytokeratin $5 / 6$ & D5/16/B4 & Epithelial cells & ++ \\
\hline Cytokeratin 7 & OV-TL 12/30 & Epithelial cells & +++ \\
\hline Cytokeratin 8 & $35 \beta \mathrm{H} 11$ & Epithelial cells & + \\
\hline Cytokeratin 10 & DE-K10 & Epithelial cells & - \\
\hline Cytokeratin 18 & DC 10 & Epithelial cells & +++ \\
\hline Cytokeratin 19 & BA17 & Epithelial cells & ++ \\
\hline Cytokeratin 20 & Ks20.8 & Epithelial cells & + \\
\hline Epithelial Membrane Antigen (EMA) & E29 & Epithelial cells & + \\
\hline Carcinoembryonic antigen (CEA) & II-7 & Ductal cells & - \\
\hline Melanosome & HMB-45 & Melanocytes & - \\
\hline Placental alkaline phosphatase (PLAP) & $8 A 9$ & Placenta & - \\
\hline S100 & & Glial cells & - \\
\hline Vimentin & V9 & Mesenchymal cells & + \\
\hline CD5 & CD5/54/F6 & T lymphocytes, Thymus & + \\
\hline CD20cy & L26 & B lymphocytes & - \\
\hline CD30 & Ber-H2 & Ki-1 lymphocytes & - \\
\hline CD45 (LCA) & 2B11+PO7/26 & Leukocytes & - \\
\hline CD45R0 & UCHL-1 & T lymphocytes & - \\
\hline CD117 (c-Kit) & & C-Kit & - \\
\hline Interleukin-6 (IL-6) & & IL-6 producing cells & +++ \\
\hline Interleukin-8 (IL-8) & 6217.11 & IL-8 producing cells & +++ \\
\hline RANTES & & Rantes producing cells & +++ \\
\hline
\end{tabular}


Table 2. Secreted Cytokine Concentrations of ThyL-6 Cells

\begin{tabular}{lrlr}
\hline \multicolumn{1}{c}{ Cytokine } & \multicolumn{2}{c}{ Concentration $(\mathrm{pg} / \mathrm{ml})$} \\
\hline IL-6 & 88,800 & \pm & 3,111 \\
IL-8 & 88,350 & \pm & 15,203 \\
RANTES & 526 & \pm & 237 \\
STNF $\alpha$-receptor I & 542 & \pm & 57 \\
IL-1 $\alpha$ & 502 & \pm & 132 \\
VEGF & 9,625 & \pm & 1,803 \\
Eotoxin & $<3.9$ & & \\
\hline
\end{tabular}

Data represents mean \pm SD from 2 different experiments. 


\section{Figure legends.}

Figure 1. Immunohistochemical staining of ThyL-6 cells. To investigate the expression profiles of ThyL-6 cells, the cells were attached to an 8-chamber slide and were treated with several primary antibodies and then visualized using a HISTOFINE SAB-PO kit according to the manufacturer's protocol. CEA: carcinoembryonal antigen, CK:

cytokeratin, EMA: epithelial membrane antigen, PLAP: placental alkaline phosphatase.

Figure 2. Cytokine secretion profiles in ThyL-6 cell line detected by a cytokine antibody array. The supernatant in which ThyL-6 cells had been cultured for 4 days was collected and the secreted cytokine profiles were detected using a TranSignal Human Cytokine Antibody Array 3.0 kit. RPMI 1640 with 10\% FBS was used as an untreated control. The lower panel represents the list of cytokines plotted on the array membrane. neg: negative control, pos: positive control.

Figure 3. Immunohistochemical staining of inflammatory cytokines. Cells attached to an 8-chamber slide were fixed with $10 \%$ formaldehyde, and the cells were stained with anti-human IL-6, IL-8, or RANTES antibodies, respectively, and then visualized using a HISTOFINE SAB-PO kit.

Figure 4. Chromosome analysis of ThyL-6 cells. The typical karyotype of ThyL-6 cells was 51, XY, +3, i(3) (q10), +7, add(7)(q11), dic(7)t(7;17)(p11;p11), +8, add(8)(p11), i(8)(q10), -9, -13, +15, i(15)(q10), der(16)t(1;16)(q11;q24), der(16)t(9;16)(q11;q24), add(21)(p11), der(?)t(?;q11), +2mar [18] / 51, idem, -der(?)t(?;q11), +mar [2]. 
Figure 5. (A) Cell growth curve of ThyL-6 cells. 1 x $10^{5}$ cells/ml of ThyL-6 cells were cultured in RPMI 1640 medium with 10\% FBS, and the cell growth was evaluated by the trypan-blue dye exclusion method. Data represent the mean \pm SD of triplicate cultures. (B) Growth inhibition of ThyL-6 cells in the presence of neutralizing antibodies. Trypsinized exponential growing cells were seated on a 96-well plate at a concentration of $1 \times 10^{5}$ cells and incubated overnight. Following the pre-incubation, the cells were washed three times with PBS and resuspended in fresh medium including neutralizing IL-6 or IL-8 antibodies at a final concentration of $10 \%, 1 \%$, or $0.1 \%$ of culture medium. The cells were incubated for an additional $24 \mathrm{~h}$, and the growth inhibition was investigated using an MTT assay. Data represent the mean \pm SD of triplicate cultures. $*$ indicates growth rate significantly decreased $(\mathrm{p}<0.05)$ in comparison with that of the untreated control cells. CTR: control, Ab: antibody.

Figure 6. (A) Western blotting detection of IL-6 in the cultured supernatant of ThyL-6 cells. The supernatant was resolved with $15 \%$ of SDS-PAGE, and the separated proteins were transferred onto PVDF membrane. The membrane was incubated with anti-human IL-6 monoclonal antibody. Secondary antibodies conjugated to HRP and a BM Chemiluminescence Western Blotting Kit were used to develop images in a Chemiluminescence Image Analyzer. (B) Cell growth of IL-6-dependent ILKM-3 cells in the presence of condition medium of ThyL-6 cells. Cells were cultured in RPMI 1640 medium with $10 \%$ FBS in the presence or absence of appropriate concentrations of ThyL-6 condition medium. Cell growth was detected by an MTT assay kit. The percentage of ThyL-6 condition medium shown represents the final concentration in the 
culture medium. Data represent the mean \pm SD from three independent experiments.

Figure 7. Heterotransplantation of ThyL-6 cells into a nude mouse. (A) A representative view of tumor (arrow) in the back of a nude mouse. (B) Cross-section of subcutaneous tumor mass lesion in a nude mouse. (C) A microscopic examination of the tumor produced in a nude mouse (low power magnification view) with hematoxylin and eosin staining. Tumor cells had proliferated with small amount of interstitial fibrous connective tissue. Liquefactive necrotic tissue was seen in the tumor mass (arrow head). (D) High power magnification view of the established tumor. Polymorphic cells with round or oval nuclei and a large round nucleolus had proliferated by mitosis, and neutrophils had infiltrated into the tumor nests. 
Fig. 1
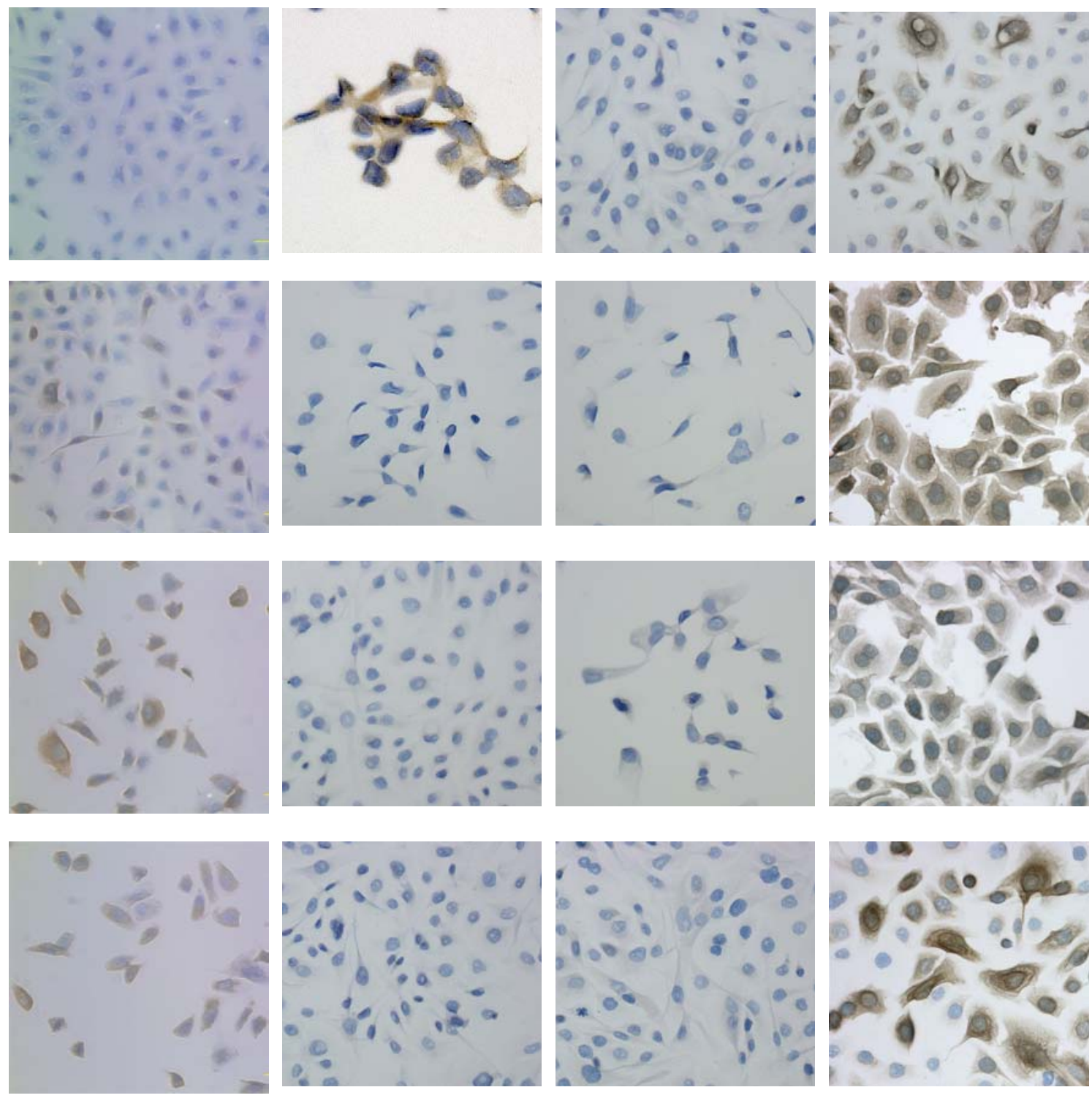

\begin{tabular}{l|l|l|l}
\hline Control & CD5 & CEA & CK5/6 \\
\hline EMA & CD45 & Melanosome & CK7 \\
\hline Pan CK & CD45R0 & PLAP & CK19 \\
\hline Vimentin & CD20cy & CD30 & CK20 \\
\hline
\end{tabular}


Fig. 2

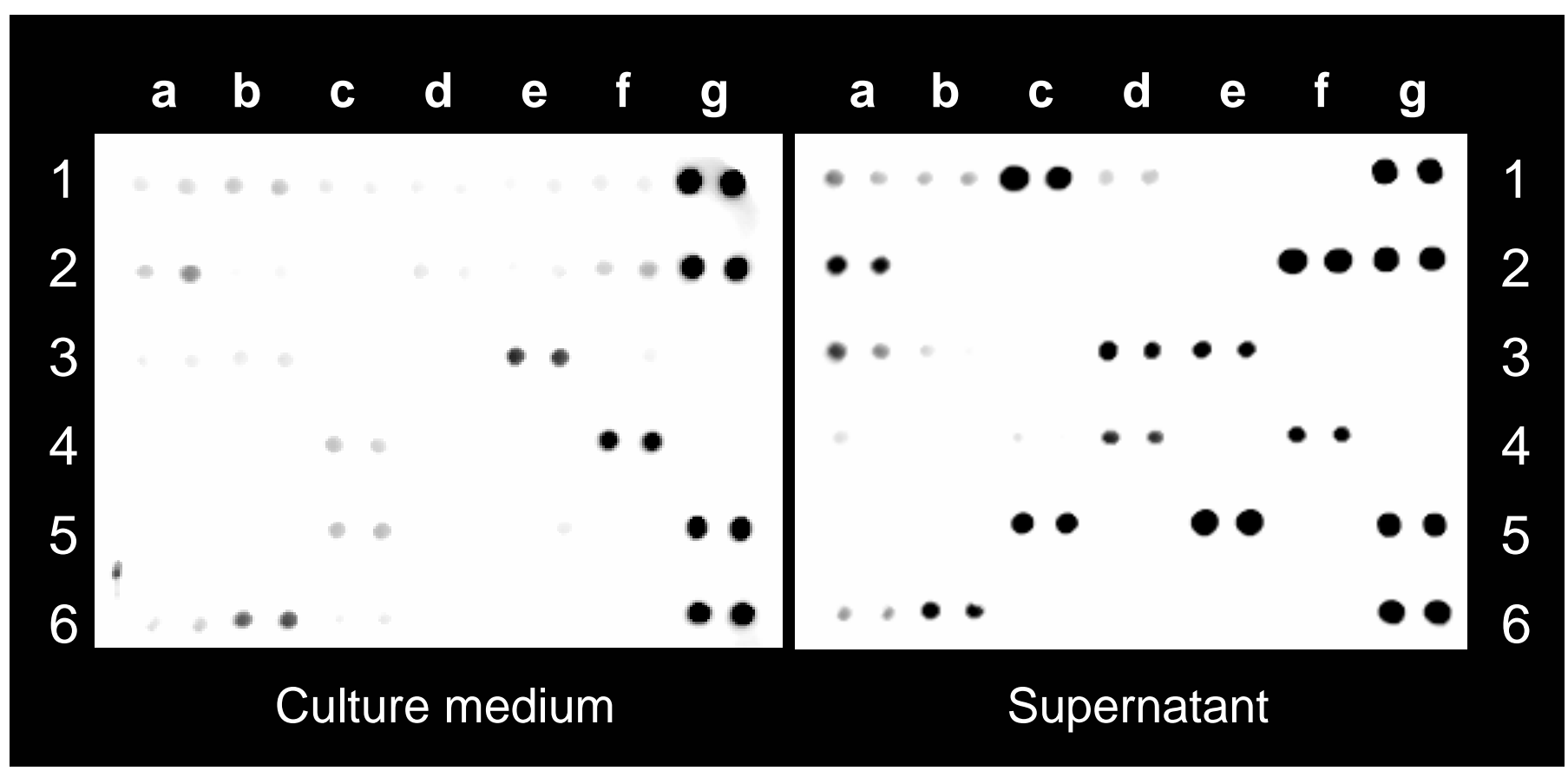

\begin{tabular}{|c|c|c|c|c|c|c|c|}
\hline & $\mathbf{a}$ & $\mathbf{b}$ & $\mathbf{c}$ & $\mathbf{d}$ & $\mathbf{e}$ & $\mathbf{f}$ & $\mathbf{g}$ \\
\hline $\mathbf{1}$ & Apo1/Fas & Leptin & RANTES & ICAMP-1 & IL-2 & IL-7 & pos \\
\hline $\mathbf{2}$ & CTLA & MIP1 $\alpha$ & TGF $\beta$ & VCAMP-1 & IL-3 & IL-8 & pos \\
\hline $\mathbf{3}$ & Eotoxin & MIP1 $\beta$ & IFN $\gamma$ & VEGF & IL-4 & IL-10 & neg \\
\hline $\mathbf{4}$ & GM-CSF & MIP-4 & TNF $\alpha$ & IL-1 $\alpha$ & IL-5 & IL-12 & neg \\
\hline $\mathbf{5}$ & EGF & MIP-5 & TNFR I & IL-1 $\beta$ & IL-6 & IL-15 & pos \\
\hline $\mathbf{6}$ & IP-10 & MMP3 & TNFR II & IL-1R $\alpha$ & IL-6R & IL-17 & pos \\
\hline
\end{tabular}


Fig. 3
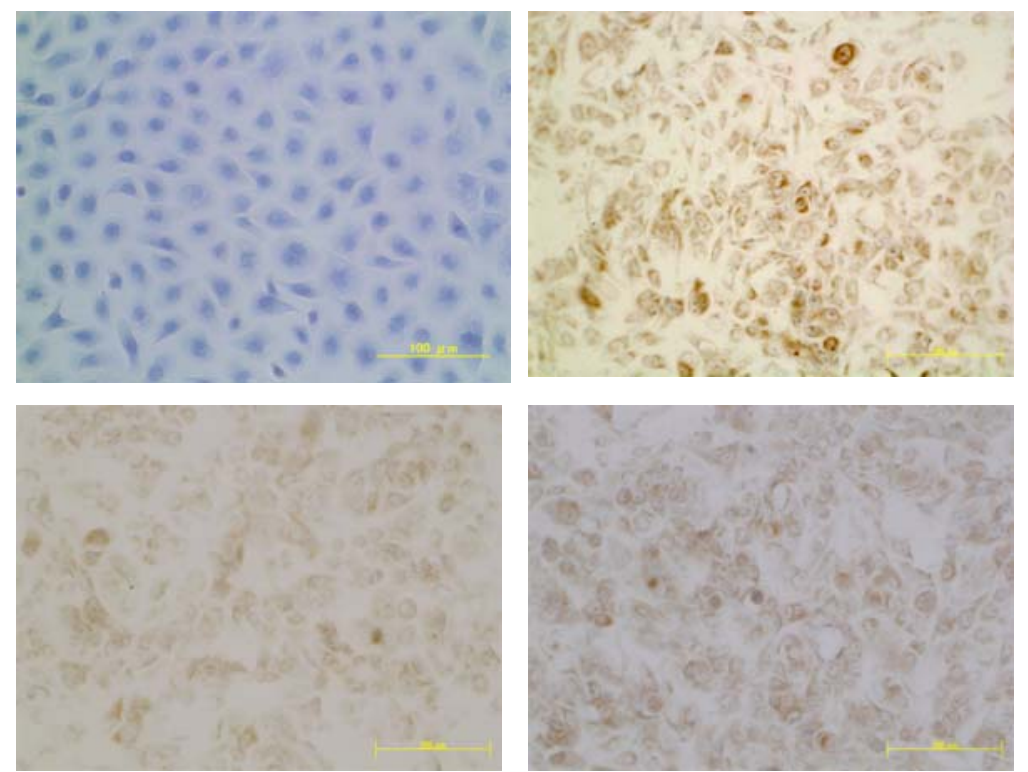

\begin{tabular}{l|l} 
Control & IL-6 \\
\hline IL-8 & RANTES
\end{tabular} 
Fig .4

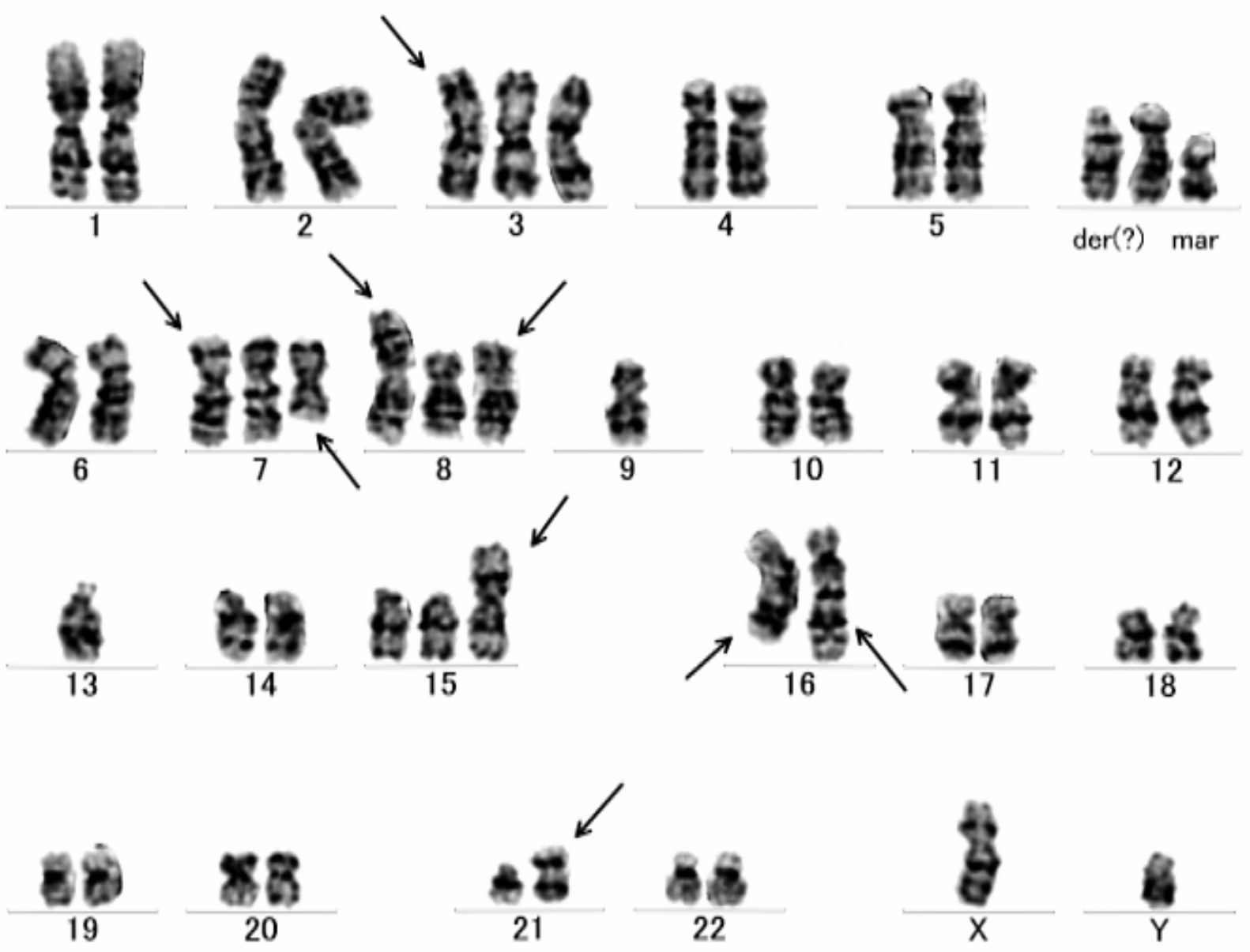


Fig. 5
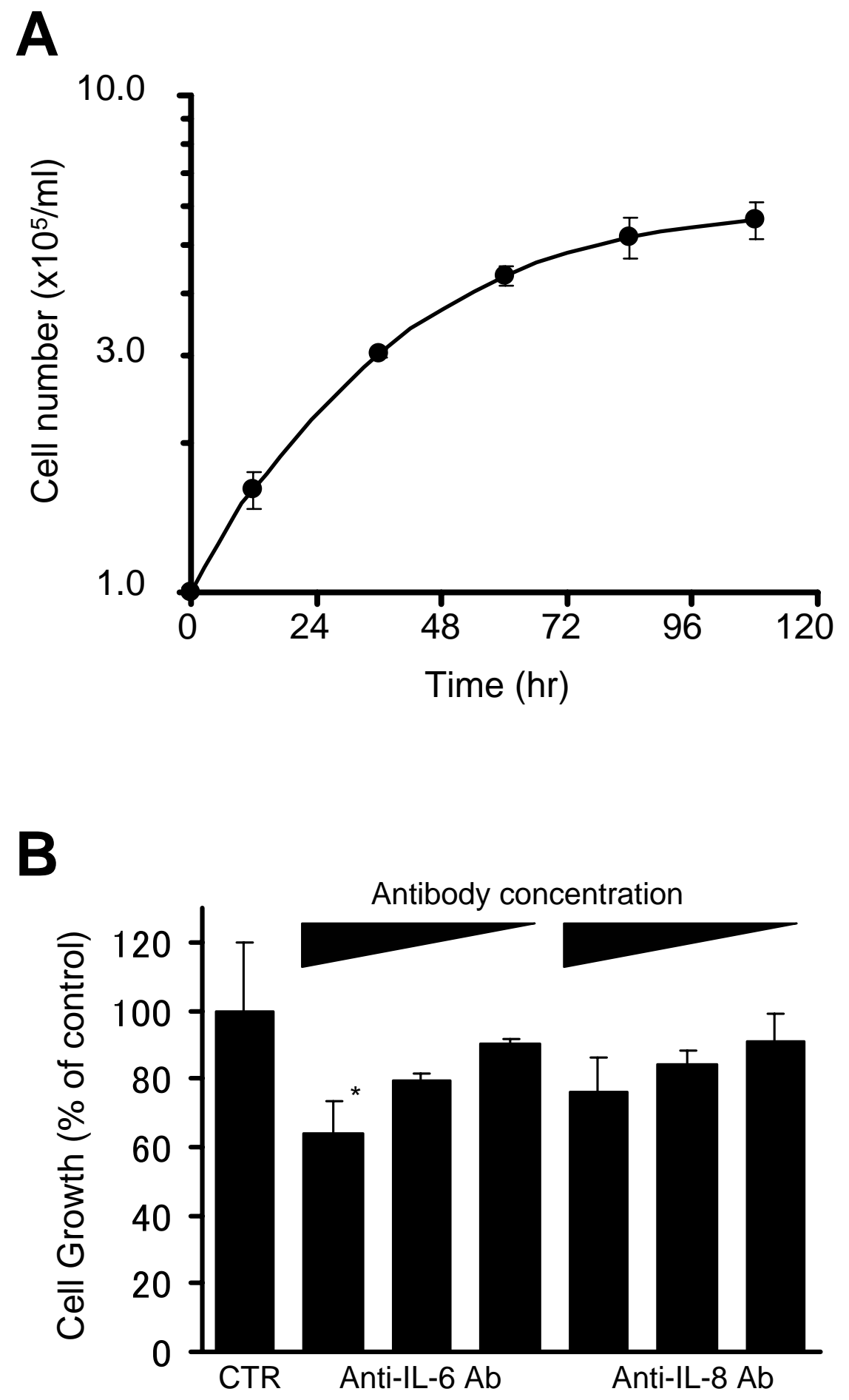
Fig. 6

A

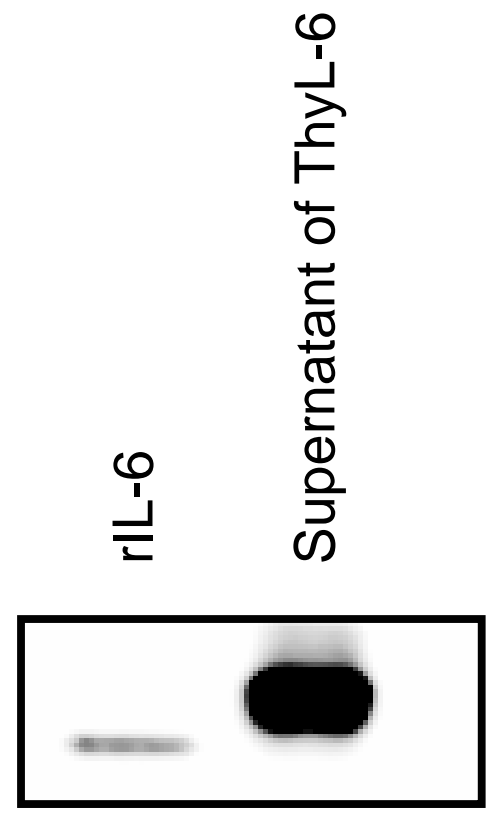

B

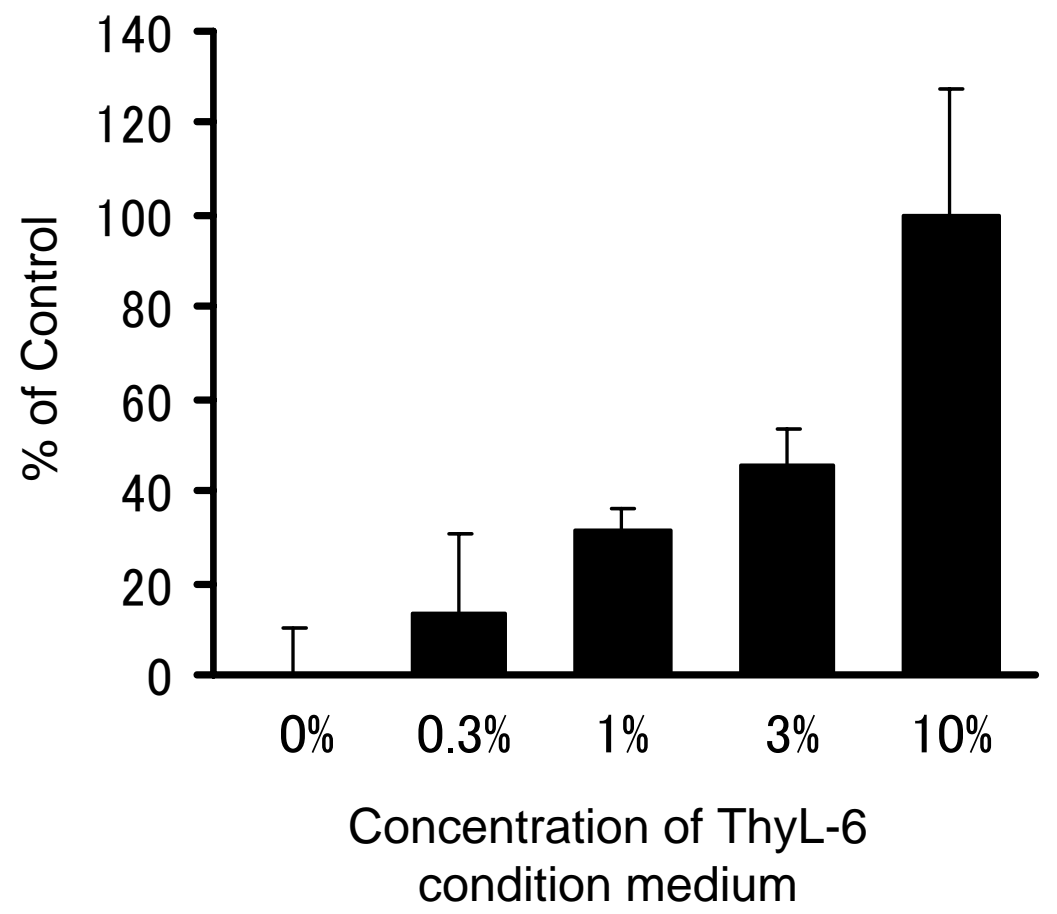


Fig. 7

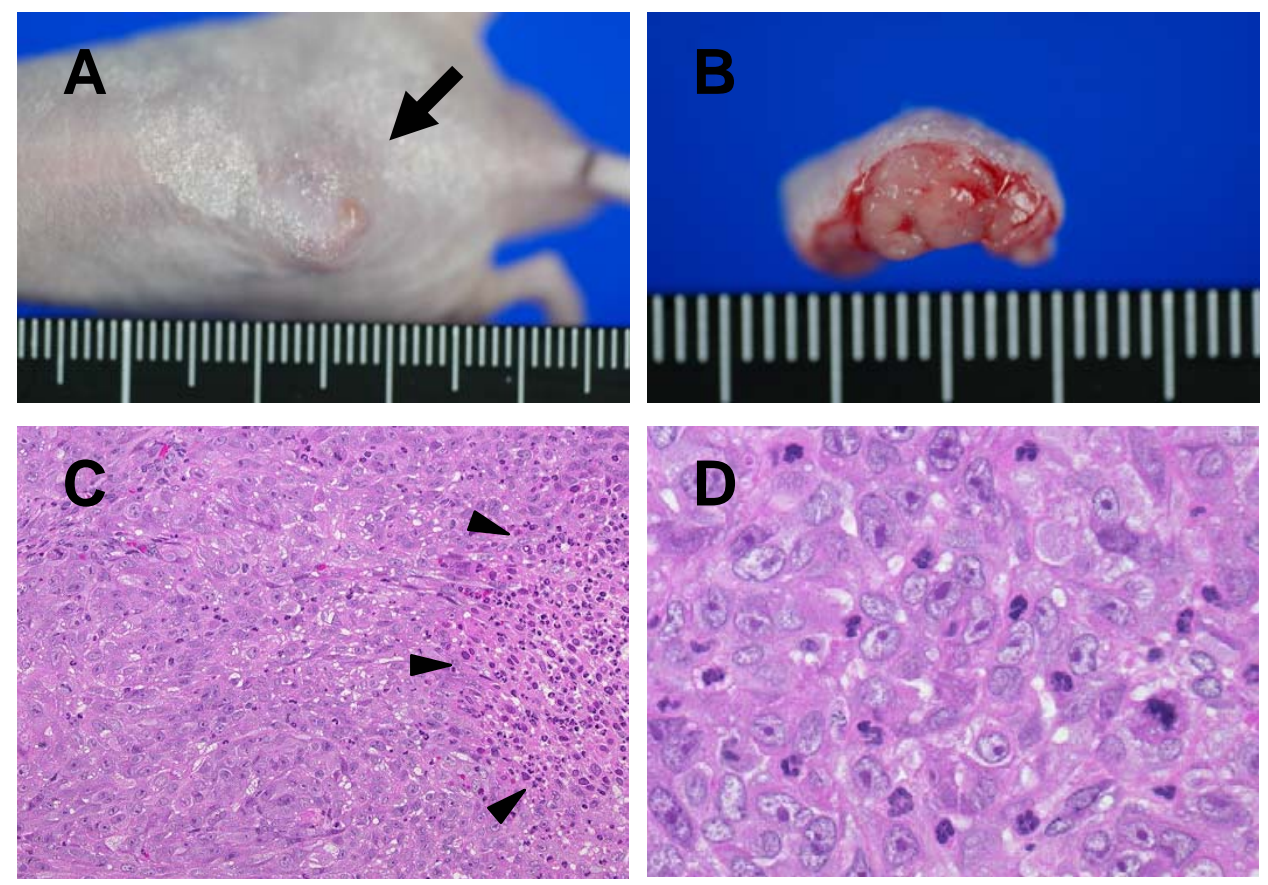

